\title{
LEIS E DIRETRIZES PARA O TRANSPORTE TERRESTRE DE CARGAS PERIGOSAS NO BRASIL
}

\author{
Henrique Sartori ${ }^{1}$ \\ Carol Cardoso Moura Cordeiro
}

RESUMO: Esse artigo tem como objetivo mostrar para o público algumas das leis e orientações do transporte de cargas perigosas no Brasil que é um dos países com leis mais exigentes sobre o assunto, dando enfoque na legislação e na classificação dos produtos como: explosivos (pólvora), inflamáveis (gasolina), gases (GLP) e radioativos (urânio). São apresentadas também as normas da Associação Brasileira de Normas Técnicas (ABNT) para fiscalização do transporte dessas cargas. Esse tipo de transporte é um caso particular da logística necessitando de uma atenção maior para que possa ser executado de forma segura zelando pelo meio ambiente e pela saúde das pessoas.

Palavras Chaves: Cargas perigosas. Transporte. Classificação. Fiscalização.

\section{INTRODUÇÃO}

O transporte de cargas é um serviço fundamental para todos os setores da economia pois, sem ele os produtos não chegariam aos consumidores, as indústrias não produziriam e os fornecedores não teriam como entregar as mercadorias.

É amplo o campo que o transporte de cargas abrange, podendo transportar grãos, materiais de construção, perecíveis, eletroeletrônicos, produtos perigosos, etc. O Brasil sendo um dos maiores países do mundo em extensão territorial e também um dos maiores produtores de commodities, tem como principal forma de escoamento o modo rodoviário contando com uma frota circulante de aproximadamente 2 milhões de caminhões.

No entanto não há apenas a circulação de cargas simples no país mas também frota de veículos que transportam cargas perigosas ou cargas IMO (Organização Marítima Internacional), os produtos perigosos podem reagir quimicamente durante as operações de

\footnotetext{
${ }^{\text {I }}$ Graduando em Engenharia de Transportes. Universidade Federal de Mato Grosso -UFMT.

${ }^{2}$ Orientadora. Universidade Federal de Mato Grosso-UFMT.
} 
transporte, armazenamento temporário, transbordo, vazamentos, e se colocados em contato com outra substância, incluindo água e ar (ANDAV 2018).

Devido ás condições necessárias para o transporte de produtos perigosos (TPP) há leis e diretrizes que foram criadas com base nas recomendações das Nações Unidas, complementadas pelas normas da ABNT juntamente com o Inmetro e contando com a participação do IBAMA, com o objetivo de padronizar o transporte diminuindo assim os riscos e tornando o Brasil um dos países mais exigentes do mundo com relação ao transporte de produtos perigosos, pois acidentes causados com esse tipo de produto tendem a ser desastrosos ao meio ambiente e aos seres vivos envolvidos.

O transporte de cargas perigosas requer uma atenção diferente dos outros tipos de cargas necessitando de motoristas e funcionários treinados para lidar com adversidades como vazamentos de produtos e explosões, rotas específicas, pois há produtos que não podem ser transportados por áreas de grande densidade populacional, além de um cuidado especial na condução do veículo, pois há produtos que podem sofrer reações com o balanço do veículo.

\section{OBJETIVOS}

Esse artigo tem como objetivo mostrar o funcionamento das normas e diretrizes que regem o transporte de cargas perigosas além de apresentar à população os riscos no transporte desse tipo de carga, a importância de uma logística bem-feita para esse transporte e o treinamento necessário dos motoristas para qualquer emergência.

\section{DESENVOLVIMENTO}

Segundo a NBR 7500 imposta pela ABNT e o DNIT (Departamento Nacional de Infraestrutura de Transportes), determina-se que produtos perigosos são todos aqueles de origem química, biológica ou radiológica que possam causar danos ao meio ambiente, população ou a seus bens.

Conforme diz a ANTT (Agência Nacional de Transportes Terrestres) pela resolução 5.232, publicada em 2016, "A classificação de um produto ou artigo como perigoso para fins de transporte deve ser feita pelo seu fabricante ou expedidor, orientado pelo fabricante, ou ainda, pela autoridade competente, quando aplicável, tomando como base as características 
físico-químicas do produto". Para efetuar a classificação correta é necessário levar em consideração o tipo de risco e a gravidade desse risco, encaixando a carga em uma classe e uma subclasse. Também de acordo com os riscos as substâncias perigosas ficam designadas a números da ONU e nomes, que orientam o embarque e o transporte utilizado, é chamado número ONU o código numérico, constituído de quatro dígitos, pelo qual determinada matéria será conhecida mundialmente.

\section{I Classes e Subclasses}

\section{Classe r: Explosivos}

- Subclasse I.I: Substâncias e artigos com risco de explosão em massa;

- Subclasse I.2: Substâncias e artigos com risco de projeção, mas sem risco de explosão em massa;

- Subclasse 1.3: Substâncias e artigos com risco de fogo e com pequeno risco de explosão ou de projeção, ou ambos, mas sem risco de explosão em massa;

- Subclasse I.4: Substâncias e artigos que não apresentam risco significativo;

- Subclasse 1.5: Substâncias muito insensíveis, com risco de explosão em massa;

- Subclasse 1.6: Artigos extremamente insensíveis, sem risco de explosão em massa.

- Muito utilizada em eventos pirotécnicos, a pólvora é um dos explosivos mais conhecidos e perigosos que existe.

\section{Classe 2: Gases}

- Subclasse 2.I: Gases inflamáveis;

- Subclasse 2.2: Gases não-inflamáveis, não-tóxicos;

- Subclasse 2.3: Gases tóxicos.

- Dissolvidos, liquefeitos, refrigerados, aerossóis, propano, butano, são alguns dos gases citados pelas subclasses.

\section{Classe 3: Líquidos inflamáveis (sem subclasses)}

- Gasolina (inserida ao número ONU em 2016 pela ANTT) 
Classe 4: Sólidos inflamáveis, substâncias sujeitas à combustão espontânea; e substâncias que, em contato com água, emitem gases inflamáveis:

- Subclasse 4.r: Sólidos inflamáveis, substâncias autorreagentes e explosivos sólidos insensibilizados;

- Subclasse 4.2: Substâncias sujeitas à combustão espontânea;

- Subclasse 4.3: Substâncias que, em contato com água, emitem gases inflamáveis.

- Dióxido de titânio pode ser altamente inflamável em contato com o ar.

\section{Classe 5: Substâncias oxidantes e peróxidos orgânicos:}

- Subclasse 5.I: Substâncias oxidantes;

- Subclasse 5.2: Peróxidos orgânicos.

- Peróxido de hidrogênio (água oxigenada), é capaz de liberar oxigênio permitindo combustão de outros materiais.

\section{Classe 6: Substâncias tóxicas e substâncias infectantes:}

- Subclasse 6.I: Substâncias tóxicas;

- Subclasse 6.2: Substâncias infectantes.

- Vacinas podem passar de uma substância que salva vidas a um material perigoso, por ser composta de microrganismos

\section{Classe 7: Material radioativo (sem subclasses)}

- Urânio.

- Material Físsil.

\section{Classe 8: Substâncias corrosivas (sem subclasses)}

- Chumbo.

- Zinco.

- Mercúrio. 
Classe 9: Substâncias e artigos perigosos diversos, incluindo substâncias que apresentem risco para o meio ambiente (sem subclasses).

- Bateria de lítio.

- Amianto

\subsection{GRUPOS DE EMBALAGENS}

Diante dessa distribuição de classes e subclasses, muitas das substâncias apresentam riscos diretos ao meio ambiente. Estes devem ser transportados de acordo com o regulamento proposto para a devida segurança, considerando seus riscos e critérios. Para fins de embalagens, substâncias que não pertencerem à classe dos explosivos, gases e materiais radioativos e às subclasses dos peróxidos orgânicos e substâncias infectantes e não forem reagentes a produtos inflamáveis, devem ser impostas a um dos Grupos de Embalagem, de acordo com o seu nível de risco apresentado:

- Grupo de Embalagem I: Substâncias colocadas em escala de alto risco.

- Grupo de Embalagem II: Substâncias colocadas em escala de médio risco.

- Grupo de Embalagem III: Substâncias colocadas em escala de baixo risco.

Produtos perigosos que apresentam riscos específicos a uma classe ou subclasse, são direcionados a elas e assim determinado seu nível de risco (Grupo de Embalagem) caso seja necessário.

\subsection{NÚMERO ONU}

O número ONU se dá por um número de série determinado pela Organização das Nações Unidas (ONU), para identificar produtos que oferecem perigo a vida e ao meio ambiente. É chamado de Registro Geral de um produto perigoso. Combinado ao número ONU se localiza o rótulo de risco que é específico para a identificação da natureza perigosa da carga, compondo o chamado painel de segurança que especifica através de identificações inseridas no veículo transportador que permite que qualquer civil observe o produto que está sendo transportado. 


\subsection{FISCALIZAÇÃO}

Sabendo da extrema importância que é manter a regularidade do transporte de cargas perigosas no Brasil, a ANTT, entidade integrante da Administração Federal Indireta, foi criada em 200I pela Lei no 10.233 , de 05 de junho de 2001, regulamentada pelo Decreto no 4.130, de 13 de fevereiro de 2002. De acordo com os artigos 22 e 24 da Lei no. I0233/or, constituem esferas de atuação da ANTT o transporte de cargas especiais e perigosas em rodovias e o estabelecimento de padrões e normas técnicas complementares relativos às operações de transporte terrestre de cargas especiais e perigosas.

O transporte rodoviário de produtos perigosos faz interligação com inúmeras outras legislações, principalmente pela competência de órgãos para a movimentação e controle do produto.

São de atendimento obrigatório as seguintes Normas Técnicas da Associação Brasileira de Normas Técnicas - ABNT, referenciadas na regulamentação da ANTT:

- ABNT NBR 750o - Identificação para o transporte terrestre, manuseio, movimentação e armazenamento de produtos;

- ABNT NBR 7503 - Transporte terrestre de produtos perigosos - Ficha de emergência e envelope - Características, dimensões e preenchimento;

- ABNT NBR 9735 - Conjunto de equipamentos para emergências no transporte terrestre de produtos perigosos;

- ABNT NBR 10271 - Conjunto de equipamentos para emergências no transporte rodoviário de ácido fluorídrico;

- ABNT NBR I46ig - Transporte terrestre de produtos perigosos - Incompatibilidade química.

A fiscalização em si, compreende a verificação de alguns itens como documentos de porte obrigatório, sinalização apropriada com indicativo de que o veículo transporta de carga perigosa, estado de conservação do veículo transportador e da carga, equipamentos emergenciais e EPI's necessários e das demais exigências solicitadas.

Segundo o Manual de Fiscalização do Transporte Rodoviário Nacional e Internacional de Produtos Perigosos (TRPP), a dinâmica de fiscalização mediante aos perigos apresentados pelo tipo de transporte deve ser rigorosamente aplicada para que, além 
do cumprimento da legislação imposta às empresas que fazem o uso de produtos perigosos, seja direcionada também à saúde dos envolvidos no transporte.

\subsection{LEGISLAÇÃO FEDERAL}

De todos os países existentes o Brasil foi o primeiro deles a criar uma legislação própria para o transporte de produtos perigosos. No dia o6 de Outubro de 1983 surge o primeiro meio legal de regularizar esse tipo de atividade, o Decreto-lei 2.063, que foi regulamentado pelo decreto 88.82i e posteriormente auxiliado pelas instruções englobadas na Portaria no 29I de 3I de Maio de 1988 motivado com o acidente ocorrido no Rio de Janeiro durante o transporte de pentaclorofenato de sódio (Pó da China) que acabou deixando 6 vítimas (ARAÚJO, 200I, apud DA COSTA; RIBEIRO, 20II).

Alguns dos tópicos mais abrangentes na legislação atual estão inscritos na Seção III do Decreto 96.044 de 18 de Maio de 1988 conforme se lê abaixo:

\section{Seção III}

\section{Do Itinerário}

Art. $9^{\circ} \mathrm{O}$ veículo que transportar produto perigoso deverá evitar o uso de vias em áreas densamente povoadas ou de proteção de mananciais, reservatórios de água ou reservas florestais e ecológicas, ou em que delas sejam próximas.

Art. ı. O expedidor informará anualmente ao Departamento Nacional de Estradas e Rodagem - DNER os fluxos de transporte de produtos perigosos que embarcar com regularidade, especificando:

I - classe do produto e quantidades transportadas;

II - pontos de origem e destino.

§ Iํ- As informações ficarão à disposição dos órgãos e entidades do meio ambiente, da defesa civil e das autoridades com jurisdição sobre as vias.

$\S 2^{\mathrm{O}}$ Com base nas informações de que trata este artigo, o Ministério dos Transportes, com a colaboração do DNER e de órgãos e entidades públicas e privadas, determinará os critérios 
técnicos de seleção dos produtos para os quais solicitará informações adicionais, como frequência de embarques, formas de acondicionamento e itinerário, incluindo as principais vias percorridas.

Art. II. As autoridades com jurisdição sobre as vias poderão determinar restrições ao seu uso, ao longo de toda a sua extensão ou parte dela, sinalizando os trechos restritos e assegurando percurso alternativo, assim como estabelecer locais e períodos com restrição para estacionamento, parada, carga e descarga.

Art. I2. Caso a origem ou o destino de produto perigoso exigir o uso de via restrita, tal fato deverá ser comprovado pelo transportador perante a autoridade com jurisdição sobre a mesma, sempre que solicitado.

Art. 13. O itinerário deverá ser programado de forma a evitar a presença de veículo transportando produto perigoso em vias de grande fluxo de trânsito, nos horários de maior intensidade de tráfego.

Por fim para que o condutor deste tipo de carga esteja legalmente regularizado é necessário que este possua o Certificado de Registro e Licenciamento do Veículo (CRLV), a Carteira Nacional de Habilitação (C.N.H.), o treinamento específico para conduzir cargas perigosas (Curso Mope) e o certificado de capacitação emitido pelo Instituto Nacional de Metrologia, Qualidade e Tecnologia (INMETRO) (DA COSTA; RIBEIRO, 2oII).

\section{CONCLUSÃO}

O transporte de cargas perigosas é um caso extremamente particular da logística de mercadorias para as empresas transportadoras em geral e transportadores autônomos. Tratando-se especificamente dessa movimentação no modo rodoviário já abrangemos diversos conjuntos de leis e restrições que visam proteger, auxiliar e tornar seguro todo o processo que envolve esse tipo de produto especificando-se de acordo com a classe e/ou subclasse das cargas transportadas.

A legislação brasileira é bastante completa quando tratada a este tema cobrindo boa parte das peculiaridades relacionada aos produtos perigosos, porém ainda assim não abrange I00\% das necessidades de cada empresa sendo necessária a vigências de legislações estaduais 
e municipais, contudo nem todas as cidades possuem regulamentações específicas em para o transporte dentro de seu município.

Por fim para que esse conjunto de normas e leis possam atingir o máximo do seu objetivo é necessário que estas estejam coerentes umas com as outras não se contrariando em momento algum, o que torna a tarefa muito mais difícil do que aparenta. Atualmente o município de São Paulo (SP) possui a maior e mais completa legislação no Brasil, que se justifica ao seu conglomerado de Parques Industriais.

\section{REFERÊNCIAS}

ASSOCIAÇÃO BRASILEIRA DE NORMAS TÉCNICAS. NBR 750o: Identificação para o transporte terrestre, manuseio, movimentação e armazenamento de produtos. Rio de Janeiro, 2016.

ASSOCIAÇÃO BRASILEIRA DE NORMAS TÉCNICAS. NBR 7503: Transporte terrestre de produtos perigosos - Ficha de emergência e envelope - Características, dimensões e preenchimento. Rio de Janeiro, 2015.

ASSOCIAÇÃO BRASILEIRA DE NORMAS TÉCNICAS. NBR 9735: Conjunto de equipamentos para emergências no transporte terrestre de produtos perigosos. Rio de Janeiro, 2016.

ASSOCIAÇÃO BRASILEIRA DE NORMAS TÉCNICAS. NBR ro27r: Conjunto de equipamentos para emergências no transporte rodoviário de ácido fluorídrico. Rio de Janeiro, 2017 .

ASSOCIAÇÃO BRASILEIRA DE NORMAS TÉCNICAS. NBR 146rg: Transporte terrestre de produtos perigosos - Incompatibilidade química. Rio de Janeiro, 2017.

(DA COSTA, Ely; RIBEIRO, Paulo, 2orI). Análise da legislação sobre o transporte de produtos perigosos. Revista de literatura dos transportes, vol. 5, no 4, pp. 260-270. Disponível em:

〈https://www.researchgate.net/profile/Ely_Costa/publication/50224267_Analise_da_legisl acao_sobre_o_transporte_de_produtos_perigosos/links/574c49odo8ae8d6e6a7b6i79.pdf >. Acesso em: I8 de ago. 2019.

(SUGUWARA, Armando, 2018). Regras e boas práticas da logística e transporte de produtos químicos/ produtos perigosos e/ou não perigosos. ANDAV, Agência nacional dos distribuidores de insumos agrícolas e veterinários. Disponível em: 
<https://www.andav.com.br/wp-content/uploads/2018/o8/MANUAL-DETRANSPORTES-_30_o8_2018.pdf >. Acesso em: Is de ago. 2019.

FETCESP. Perguntas mais frequentes sobre o transporte de produtos perigosos. Disponível em:〈http://www.guiadotrc.com.br/guiaperig/pmaisfrequentespp.pdf $\rangle$. Acesso em: 17 de ago. 2019.

TRANSPORTE DE CARGAS - TUDO O QUE VOCÊ PRECISA SABER PARA SE DAR BEM. $\quad$ Trekken. $\quad$ Disponível em 〈http://www.trekken.com.br/web/noticias/transporte-de-cargas/>. Acesso em: i7 de ago. 2019. 